\title{
Energy transferred to the substrate surface during reactive magnetron sputtering of aluminum in $\mathrm{Ar} / \mathrm{O}_{2}$ atmosphere
}

\author{
A.L. Thomann ${ }^{a^{*}}$, P.A. Cormier ${ }^{a}$, V. Dolique ${ }^{b}$, N. Semmar ${ }^{a}$, R. Dussart ${ }^{a}$, T. Lecas ${ }^{a}$, B. Courtois ${ }^{c}$, P. \\ Brault $^{\mathrm{a}}$ \\ ${ }^{\text {a} G R E M I, ~ U M R ~} 7344$ du CNRS et de l'Université d'Orléans, 14 rue d'Issoudun, B.P. 6744, 45067 \\ Orléans cedex 2, France \\ bLEMA, Université Claude Bernard Lyon I, campus de la DOUA, bâtiment Virgo 7 avenue Pierre \\ de Coubertin, 69622 Villeurbanne cedex, France \\ ${ }^{\mathrm{c} C E M H T I, ~ U P R} 3079$ du CNRS, 1D avenue de la Recherche Scientifique, 45071 Orléans cedex2, \\ France
}

*Corresponding author. Tel. +33 2384948 70; e-mail: anne-lise.thomann@,univ-orleans.fr

\begin{abstract}
A study of the reactive sputtering of aluminum was carried out by coupling energy flux measurements at the substrate location with conventional diagnostics of the gas phase and analyses of the deposited films. The main purpose was to get some insight into the elementary mechanisms involved at the substrate surface during the film growth in the well known metal and oxide regimes and at the transitions from one to another. Measurements were carried out in front of a $10 \mathrm{~cm} \mathrm{Al}$ target at a power of $400 \mathrm{~W}$ (i.e. $5 \mathrm{~W} / \mathrm{cm}^{2}$ ) and a total pressure of $0.6 \mathrm{~Pa}$. The flow rate ratio $\left(\mathrm{O}_{2} / \mathrm{O}_{2}+\mathrm{Ar}\right)$ was varied in the range 0 to $50 \%$. Different kinetics and values of energy transfer, denoting different involved mechanisms, were evidenced at metal-oxide (increasing flow rate) and oxide-metal (decreasing flow rate) transitions. The metal-oxide transition was found to be a progressive process, in agreement with optical emission spectroscopy and deposit analysis, characterized by an increase of the energy flux that could be due to the oxidation of the growing metal film. On the contrary, oxide-metal transition is abrupt, and a high energy released at the beginning that could not be attributed to a chemical reaction. The possible effect of $\mathrm{O}^{-i}$ ions at this step was discussed.
\end{abstract}

Keywords: reactive magnetron sputtering of aluminum; real-time energy flux density measurements; oxide thin film growth; energy transfer in thin film deposition. 


\section{Introduction}

Reactive magnetron sputtering is one of the techniques allowing the deposition of compound thin films [1-4]. Most of works dealing with this method are focused on the target sputtering process and discharge parameter evolution [5-7]. Studies on deposition of $\mathrm{Al}_{2} \mathrm{O}_{3}$ by reactive magnetron sputtering have shown the change of the target sputtering regime depending on the amount of oxygen in the gas phase. $[4,6,8]$. A transition from metal to oxide regime has been evidenced and a hysteresis phenomenon is usually observed when following the discharge parameters with respect of the reactive gas flow rate. These trends are typical of conventional DC magnetron reactive sputter deposition. The film features depending on the growth regime have been studied by several authors $[8,9]$.

It is well known that thin film growth widely depends on physical and chemical mechanisms which transfer energy to the growing film. In his structure zone diagram Thornton $[10,11]$ showed that the morphology of the thin film was drastically influenced by the substrate temperature and the energy brought by the energetic species assisting the growth. The knowledge of energetic conditions at the substrate is thus of particular relevance for the understanding of thin film growth mechanisms [12]. Their control is therefore a key aspect for tailoring the film properties to the envisaged application(s). Estimation of the energy deposited at the substrate during plasma magnetron sputtering is a quite old issue $[13,14]$. This can be done either by energy balances, carried out from data of the gas phase (specie density, flux and energy), or by measurements performed with specific probes $[12,15-19]$. In magnetron sputtering processes, calorimetric probes, based on the recording of the temperature evolution, have been widely used [16,17,20-22]. The main drawbacks of this type of probe are the quite long acquisition time (several minutes), preventing from the detection of low intensity or transient energetic contributions, and the impossibility to perform real time measurements [23].

In the present study we have performed energy flux measurements at the substrate location during reactive sputter deposition by means of an energy flux diagnostic (thermopile, $300 \mu \mathrm{s} \mathrm{time}$ resolution) previously used in several low pressure plasmas [23-26]. The main goal was to study the energy transfer in both deposition regimes and especially during the transitions from one to the other. These measurements will give better insight into the mechanisms involved in thin film growth process. First the energy transferred by oxidation to a pure aluminum thin film in $\mathrm{O}_{2}$ atmosphere was measured. Second, the hysteresis phenomenon was investigated in the reactive sputtering of Al target and compared to the evolution of the discharge voltage and to optical emission spectroscopy data. Finally, material analyses were carried out on deposits synthesized at 
various $\mathrm{O}_{2}$ percentages.

2. Experimental procedure

The magnetron sputtering system (APRIM VIDE Company) is given in figure 1. It has been widely described in a previous work [27]. Pure aluminum target (99.5\%) with a $10 \mathrm{~cm}$ diameter was used. The target surface was $30^{\circ}$ tilted with respect to the substrate surface plan and was powered with a DC power supply (Pinnacle+, Advanced Energy). The flow rate ratio $\mathrm{O}_{2} /\left(\mathrm{O}_{2}+\mathrm{Ar}\right)$ was varied between $0.5 \%$ and $50 \%$ keeping constant the power and the pressure, $400 \mathrm{~W}\left(\approx 5 \mathrm{~W} / \mathrm{cm}^{2}\right)$ and 0.4 $\mathrm{Pa}$, respectively. In order to study the hysteresis phenomenon the $\mathrm{O}_{2}$ percentage in the gas phase was successively increased and decreased. The change of gas mixture was always done when the discharge was off. Energy flux measurements were carried out with a heat flux diagnostic developed at GREMI laboratory which consists of a commercial Heat Flux Micro sensor (HFM) inserted in a cooled shaft [28]. HFM is composed of a Pt100 temperature sensor and a thermopile having a time resolution of $300 \mu \mathrm{s}$. The high sensitivity, less than $1 \mathrm{~mW} / \mathrm{cm}^{2}$ is provided by a high number of thermocouple junctions (1600 junctions $\left./ \mathrm{cm}^{2}\right)$. For all experiments, a $6 \mathrm{~mm}$ diameter thin copper substrate was stuck on the active area of the heat flux diagnostic. During energy flux measurements the HFM was cooled down to $5^{\circ} \mathrm{C}$ in order to avoid a rise of its self temperature that would induce heat losses mainly by IR emission. This point is detailed in [28]. The substrate holder and the heat flux diagnostic were alternatively placed in front of the magnetron target at a distance of $9 \mathrm{~cm}$. The voltage of the copper substrate was left floating.

Optical emission spectroscopy technique (OES) was used to qualitatively study the presence of aluminum and oxygen species in the gas phase. Three lines were monitored at the cathode position (detection area at the center of the target), the Ar I line at $750 \mathrm{~nm}$, the Al I line at $396 \mathrm{~nm}$ and the O I at $777 \mathrm{~nm}$. A BWTek BCT110E (resolution of $1 \mathrm{~nm}$ ) spectrometer was used. It is sensitive to emission in the wavelength range 300-900 $\mathrm{nm}$.

Five deposition sequences were performed on silicon (100) substrates in order to analyze the chemical composition, the structural properties and the surface morphology of the deposited thin film. Four deposits (A, B, C and D) were synthesized during the increase of the $\mathrm{O}_{2}$ percentage (7.5, $15,16.5$ and $50 \%$ ) and one (E) during the $\mathrm{O}_{2}$ percentage decrease $(7.5 \%)$. The substrate voltage was left floating and the substrate temperature was not regulated. Experimental conditions corresponding to each deposit are given in table 1.

The crystalline structure of the five deposited thin films was analyzed by Grazing incidence X-ray spectroscopy (GIXRD) measurements, performed with the cobalt line $(0.17889 \mathrm{~nm})$ at an 
incidence angle of $1^{\circ}$. Rutherford backscattering spectroscopy (RBS) were performed using $\alpha$ particles of $2 \mathrm{MeV}$ extracted from a Van de Graaf accelerator in the CEMHTI laboratory (Orleans, France). RBS spectra were fited using the SIMNRA software, to estimate the number of deposited $\mathrm{Al}$ atoms and the oxygen concentration profile. The surface morphology and the film thickness were studied by scanning electron microscopy (SEM) (Carl Zeiss SMT, Supra-40, FEG-SEM). The deposition rate was evaluated by dividing the thickness measured on cross section SEM micrographs by the deposition time.

3. Results and discussion

\subsection{Sensitivity of the energy flux diagnostic}

Before studying the reactive magnetron process, we investigated the interaction between gases (argon and oxygen) and a "fresh" aluminum surface. To this purpose, an experimental protocol, divided in two steps was set up: first an aluminum thin film was deposited on the copper substrate surface by magnetron sputtering of $\mathrm{Al}$ target in pure argon. The $\mathrm{Al}$ deposition sequence lasted $5 \mathrm{~min}$ in order to deposit a film thickness of approximately $300 \mathrm{~nm}$. Then, the plasma was switched off and argon and oxygen gases were successively injected in the vessel. Fig. 2 represents the energy flux due to the interaction between gases and the freshly deposited aluminum surface.

The first $20 \mathrm{~mW} / \mathrm{cm}^{2}$ energy flux peak (1) corresponds to the injection of $\mathrm{O}_{2}$ in the gas phase. It is followed by a decrease until a steady state is reached. At the second step (2) $\mathrm{O}_{2}$ flow rate was stopped and an energy flux drop of $0.9 \mathrm{~mW} / \mathrm{cm}^{2}$ was recorded. A rise of the same value (3) was obtained when the $\mathrm{O}_{2}$ was re-injected in the chamber. At the end of the experiment, both $\mathrm{O}_{2}$ and $\mathrm{Ar}$ flow rates were stopped (4) and a drop of $1.9 \mathrm{~mW} / \mathrm{cm}^{2}$ was detected. The energy flux reached a stable value of $7.4 \mathrm{~mW} / \mathrm{cm}^{2}$, which corresponds to the radiative transfer between the aluminum thin film at $5^{\circ} \mathrm{C}$ (cooled HFM) and the surrounded surfaces at room temperature.

The first $20 \mathrm{~mW} / \mathrm{cm}^{2}$ peak can be attributed to the chemical reaction between the $\mathrm{Al}$ thin film and oxygen gas. It is supposed to be caused by the energy released by Al-O bond formation. The decrease which follows this peak is explained by the fact that the aluminum surface became fully oxidized, i.e. passivated. This hypothesis can be checked by making a rough estimation of the energy released by the oxidation $\left(\varphi_{\text {ox }}\right)$ of the aluminum thin film. Taking an enthalpy of oxidation: $\Delta \mathrm{H}_{\mathrm{ox}}=1675.7 \mathrm{~kJ} / \mathrm{mol}[29]$ : 


$$
\varphi_{o x}=\frac{2 N_{O_{2}}}{N_{a}} \Delta H_{o x} \gamma_{\text {sticking }}
$$

where $\mathrm{N}_{\mathrm{a}}$ is the Avogadro constant and $\gamma_{\text {sticking }}$ the sticking coefficient of oxygen molecules, which was found in the literature between 0.005 and 0.032 [30-33]. $\mathrm{N}_{\mathrm{O} 2}$ is the number of gas molecules hitting all reactor surfaces per time and area unit, at a given oxygen partial pressure $\left(\mathrm{p}_{\mathrm{O} 2}=0.25 \mathrm{~Pa}\right)$. $\mathrm{N}_{\mathrm{O} 2}$ is calculated using an expression coming from the gas kinetic theory [31] given in the equation 2 , and that has been utilized by several authors to estimate the oxidation rate at the target $[34,35]$.

$$
N_{\mathrm{O}_{2}}=p_{\mathrm{O}_{2}} / \sqrt{2 \pi m k T_{g}}
$$

$\mathrm{m}=2 \times 2.6578 .10^{-26} \mathrm{~kg}$ is the dioxygen mass, $\mathrm{k}$ denotes the Boltzmann constant and $\mathrm{T}_{\mathrm{g}}=300 \mathrm{~K}$ is the gas temperature.

The number of $\mathrm{Al}$ atoms susceptible to be oxidized is expected to be high compared to the oxygen molecules interacting with the surface. $\mathrm{N}_{\mathrm{O} 2}$ is thus considered to be the limiting parameter of the oxidation reaction. Consequently the reaction should stop when a protective and chemically inert oxide layer is formed at the substrate. From these equations the energy transferred to the aluminum surface by oxidation was estimated in the range: 10 to $45 \mathrm{~mW} / \mathrm{cm}^{2}$. The $20 \mathrm{~mW} / \mathrm{cm}^{2}$ peak recorded with the energy flux diagnostic is in this range and can consequently be attributed to oxidation of the aluminum surface.

Once the aluminum surface was fully oxidized, the only interaction that could occur with $\mathrm{Ar}$ and $\mathrm{O}_{2}$ gases is heat conduction ( $\left.\varphi_{\text {cond }}\right)$. Modifications of the energy flux observed in Fig. 2 (steps 2, 3 and 4) should be due to this phenomenon. The energetic contribution of gas conduction was estimated from the following expression $[16,36,37]$ :

$$
\varphi_{\text {cond }}=\sqrt{\frac{2 k}{\pi m_{g}}} \frac{a_{g} p_{g}}{\sqrt{T_{g}}}\left(T_{g}-T_{S}\right)
$$

where $T_{\mathrm{s}}$ is the HFM surface temperature regulated at $278 \mathrm{~K}$.

Parameters used in equation 3 are given in table 2. The accommodation coefficient " $\mathrm{a}_{\mathrm{g}}$ " represents how far the atoms thermalize with the surface. It has been determined for a Pt surface for various gases [38,39]. $\varphi_{\text {cond }}$ was thus estimated in the case of argon and oxygen and found equal to 0.5 $\mathrm{mW} / \mathrm{cm}^{2}$ and $0.4 \mathrm{~mW} / \mathrm{cm}^{2}$, respectively. Taking into account the sensitivity limit of the sensor $(0.1$ $\mathrm{mW} / \mathrm{cm}^{2}$ ), the uncertainty on the knowledge of the gas partial pressure and on accommodation coefficients, these values are in quite good agreement with the energy fluxes measured at the steps 
2, $3\left(0.9 \mathrm{~mW} / \mathrm{cm}^{2}\right)$ and $4\left(1.9 \mathrm{~mW} / \mathrm{cm}^{2}\right)$. This shows that energetic contributions as small as gas conduction could be detected using the heat flux diagnostic.

In this part, we have shown that the energy transferred to a metal surface by gas conduction or chemical reaction could be detected and quantified. Indeed, it seems possible to follow in real time, elementary mechanisms taking place at the substrate surface during the film growth. This will be of particular interest for the study of reactive plasma sputter deposition processes.

\subsection{Characterization of the deposition conditions}

3.2.1. Hysteresis phenomenon in reactive magnetron sputtering of aluminum

The cathode voltage was measured with respect of the $\mathrm{O}_{2}$ percentage during reactive $\mathrm{Al}$ magnetron sputtering (see figure 3). $\mathrm{O}_{2}$ percentage was first increased and then decreased. A classical evolution of the cathode voltage was evidenced exhibiting the well known hysteresis phenomenon $[1,4,8,40]$.

The cathode voltage when $\mathrm{Al}$ is sputtered in pure argon is close to $395 \mathrm{~V}$. When the $\mathrm{O}_{2}$ percentage increases, this value remains constant until $8 \%$. Indeed, for $\mathrm{O}_{2}$ percentages in this range, $\mathrm{O}_{2}$ molecules are consumed by adsorption on the Al thin film covering the vessel surfaces. This socalled getter effect will be discussed below. Because of the sputtering process, the target surface remains clean and the main sputtered particles are metallic atoms. A slight increase of the cathode voltage between $8 \%$ and $16.5 \%$ can be noticed. D. Depla et al. [4] explained this evolution by a decrease of the ion secondary electron emission coefficient ( $\gamma$ ISEE: number of electrons emitted per incoming ion). This decrease of $\gamma$ ISEE is attributed to the formation of a chemisorbed oxide layer on the $\mathrm{Al}$ target surface before the transition.

When the $\mathrm{O}_{2}$ percentage is high enough to poison the target (16.5\%), a sharp decrease of the cathode voltage, corresponding to the metal oxide transition, is observed. For higher $\mathrm{O}_{2}$ percentages (between $16.5 \%$ and $50 \%$ ) the cathode voltage remains constant and the oxide mode is reached. A layer of aluminum oxide is formed on the target surface which induces an increase of the $\gamma$ ISEE, leading to a decrease of cathode voltage [4] until $290 \mathrm{~V}$ in our case.

The $\mathrm{O}_{2}$ percentage was finally decreased leading to a slight increase of the cathode voltage until 7.5 $\%$ of $\mathrm{O}_{2}$. This percentage corresponds to the transition between the oxide and the metal mode. The cathode voltage sharply increases to reach back the value recorded at the beginning of the metal mode.

Both transitions and hysteresis were also studied by OES measurements performed at the 
center of the cathode surface. For some critical points corresponding to both transitions $(16.5 \%$, for the increase of $\mathrm{O}_{2}$ and $7.5 \%$ for the decrease of $\mathrm{O}_{2}$ ), two OES measurements were performed: a first at $\mathrm{t}=0 \mathrm{~s}$ and a second at $\mathrm{t}=25 \mathrm{~s}$. For all other $\mathrm{O}_{2}$ percentage only one measurement at the beginning of the plasma sequence was carried out. The ratios between $\mathrm{Al}$ and $\mathrm{Ar}$ lines and $\mathrm{O}$ and $\mathrm{Ar}$ lines are represented with respect to the $\mathrm{O}_{2}$ percentage in figure 4(a) and 4(b), respectively.

The global evolutions of $\mathrm{O} / \mathrm{Ar}$ and $\mathrm{Al} / \mathrm{Ar}$ line ratios are quite classical in reactive magnetron processes $[6,7,34]$. In the range between 0 and $16.5 \%$ of $\mathrm{O}_{2}$ corresponding to the metal mode, the $\mathrm{Al} / \mathrm{Ar}$ ratio is at its maximum (see on fig. 4(b)). In this mode, aluminum atoms are sputtered. On the contrary, one can see figure 4(a), that the $\mathrm{O} / \mathrm{Ar}$ line ratio remains constant at its minimum. Indeed, oxygen atoms are gettered by the aluminum deposited on the surrounded surfaces (walls, target, substrate...) and only a low amount of oxygen atoms is present in the gas phase $[1,6,41]$. For $\mathrm{O}_{2}$ percentage higher than $16.5 \%$, the metal-oxide transition takes place. At this step, $\mathrm{O}_{2}$ cannot be gettered anymore and the $\mathrm{O} / \mathrm{Ar}$ line ratio increases. The target, as well as other surfaces in the vessel, gets oxidized. $\mathrm{AlO}_{\mathrm{x}}$ compounds begin to be sputtered or are formed by chemical reaction in the plasma, reason why the Al/Ar ratio sharply decreases. This is observed on the measurement performed at $\mathrm{t}=0 \mathrm{~s}$. As mentioned before, a measurement was also done $25 \mathrm{~s}$ later at this $\mathrm{O}_{2}$ percentage. It is seen in Fig. 4 that after $25 \mathrm{~s}$ of plasma both ratios tend to recover the value of the metal regime. This can be explained as follows: at $16.5 \%$ the amount of $\mathrm{O}_{2}$ is sufficient to induce the formation of $\mathrm{Al}_{2} \mathrm{O}_{3}$ on the target surface. But, since sputtering of the target also takes place, formation and destruction of this oxide are in competition. The huge variation of both line ratios at the conditions of formation of $\mathrm{Al}_{2} \mathrm{O}_{3}$ and $\mathrm{t}=0$ indicates that no progressive oxidation of $\mathrm{Al}$ is able to occur. The target surface turns abruptly from metallic to oxidized state. This can be correlated to the oxidation properties of aluminum, which does not form any reduced oxides [4,6]. But if the sputtering plasma goes on interacting with the target, this oxide is removed and the metal mode is recovered. Thus at this $\mathrm{O}_{2}$ percentage, the discharge parameters and the sputtering conditions would evolve with the plasma time duration. During the oxide mode, the O/Ar line ratio increases linearly with the $\mathrm{O}_{2}$ percentage, which is characteristic of this mode [6,7,34].

As the $\mathrm{O}_{2}$ percentage is decreased, the metal mode is reached back for $\mathrm{O}_{2}$ percentage lower than 8 $\%$. As for the first transition, two OES measurements were performed. Between these points, the $\mathrm{Al} / \mathrm{Ar}$ and $\mathrm{O} / \mathrm{Ar}$ line ratios drastically vary to reach the value of the metallic mode. At this step there is no competition between different processes: the decrease of $\mathrm{O}_{2}$ percentage in the gas phase and the action of the sputtering plasma both lead to the removal of the oxide from the target surface. Again these sharp evolutions indicate that, since no reduced oxide exits in the Al/O system [4], formation and destruction of the oxide at the target surface are very violent processes. 


\subsubsection{Energy flux density measurement in reactive sputtering of aluminum}

Fig. 5 represents the energy flux evolution with time when $\mathrm{O}_{2}$ percentage is progressively increased, then decreased. Each slot corresponds to an $\mathrm{O}_{2}$ percentage but two different protocols of measurements were used. First experiment was performed with "plasma on" sequences of $30 \mathrm{~s}$ (see Fig. 5a). In order to study the kinetic of the sputtering and deposition processes, in a second run of experiments the plasma was maintained until a steady state value was reached (see fig. 5b). On both graphs, the area corresponding to the metal-oxide transition is given in inset.

It is clearly seen on these graphs that energy fluxes are almost constant when metal or oxide modes are well established. On the contrary, they drastically vary at $16.5 \%$ (when $\mathrm{O}_{2}$ percentage increases) and $7.5 \%$ (when $\mathrm{O}_{2}$ percentage decreases). This shows that transitions and hysteresis phenomenon evidenced in discharge voltage and emission line evolutions are also detected on the variation of the energy deposited at the substrate. Values obtained in both runs of experiments (30s or steady state signals) are in excellent agreement, proving the good reproducibility of the energy flux measurements. In Fig. 6 the evolution of the energy flux density versus $\mathrm{O}_{2}$ percentage is presented.

Energy flux equals $150 \mathrm{~mW} / \mathrm{cm}^{2}$ and $95 \mathrm{~mW} / \mathrm{cm}^{2}$ in metal and oxide modes, respectively. In figure $5 b$, for steady state signals, it can be seen that the oxide mode value is reached for an $\mathrm{O}_{2}$ percentage of $16.5 \%$ and after about $35 \mathrm{~min}$ of plasma. On the other hand, for $30 \mathrm{~s}$ measurements, the $\mathrm{O}_{2}$ percentage is systematically increased after each step and the cumulated plasma "on" time to reach this oxide mode value is $7 \mathrm{~min}$. The corresponding reached $\mathrm{O}_{2}$ percentage is $40 \%$, and the transition occurs over a large range of $\mathrm{O}_{2}$ percentages (Fig. 6, closed triangles). These observations show that the kinetic of the transition between metal $\left(150 \mathrm{~mW} / \mathrm{cm}^{2}\right.$ energy flux) and oxide (95 $\mathrm{mW} / \mathrm{cm}^{2}$ energy flux) regimes depends on the experimental protocol. As the poisoning of the target is known to be the reason on the transition, this trend indicates that the oxidation process of $\mathrm{Al}$ depends both on the $\mathrm{O}_{2}$ residual pressure (i.e. oxidizing species concentration) and time of interaction with the reactive plasma. This, of course, seems to be quite reasonable. However, the study of the deposition process in conditions close to the transition indicates that deposited films could present different properties depending on the deposition time and history of the target. This fact should be taken into account, especially when a comparison between gas phase and material diagnostics is done. Indeed, gas phase diagnostics are usually implemented in a faster time (several 
seconds) than material deposition which typically requires minutes. Thus, what is detected by mean of plasma diagnostics might not be what the substrate surface was mainly submitted at.

To get better insight into both transitions, the energy flux and the cathode voltage are represented with respect to $\mathrm{O}_{2}$ percentage in figure 7 during the increase (7a) and the decrease (7b) of the $\mathrm{O}_{2}$ percentage. Whereas a slight energy flux increase is detected during the metal-oxide transition (see figure 7a), an intense peak is recorded during the oxide-metal one (see figure $7 \mathrm{~b}$ ).

As it has been explained in a previous paragraph, the increase of the target voltage before the metal-oxide transition (from $8 \%$ to $16.5 \%$ of $\mathrm{O}_{2}$ ) is attributed to the formation of a chemisorbed oxide layer on the target. At the same time, the energy deposited at the substrate remains constant, showing that this phenomenon has no effect on the energy transferred to the substrate.

However, an energy flux rise of approximately $45 \mathrm{~mW} / \mathrm{cm}^{2}$ can be seen, before the decrease corresponding to the metal-oxide transition. At this step the amount of oxygen (present in the gas phase or already trapped) is high enough so that an oxide can be formed on the metallic thin film deposited on the substrate surface. This exothermic reaction should induce an energy transfer at the substrate surface similar to that detected when a fresh $\mathrm{Al}$ surface is submitted to $\mathrm{O}_{2}$ flow (see Fig. 2). With a rough estimation of the $\mathrm{O}_{2}$ partial pressure $(0.1 \mathrm{~Pa})$ the corresponding energy can be evaluated from equations 2 and 3. This gives an expected value between $4 \mathrm{~mW} / \mathrm{cm}^{2}$ and 18 $\mathrm{mW} / \mathrm{cm}^{2}$, which is lower than the measured one. However, one has to take into account that $\mathrm{O}_{2}$ molecules are partially dissociated in the plasma, and that reactive oxygen atoms interact now with the $\mathrm{Al}$ film. The effective sticking coefficient would thus be increased compared to $\mathrm{O}_{2}$ molecules and consequently the released energy would certainly be higher than the estimated one. The slow decrease of the energy flux following the peak at the transition may be due to the oxidation of the residual $\mathrm{Al}$ atoms that always partly participate to the growth. As shown from OES results, when the plasma interacts with the target surface at this step, Al/Ar line ratio tends to reach back the metal regime value. This point will be further discussed in the deposit analysis part.

At the oxide-metal transition (7.5 of decreasing oxygen percentage), an intense energy flux peak of $800 \mathrm{~mW} / \mathrm{cm}^{2}$ is detected (see on fig. $7 \mathrm{~b}$ ). This intense peak is quite different from the one obtained at the metal-oxide transition, indicating that a different mechanism occurs. Moreover, keeping in mind that all surfaces are fully passivated and that a so large increase is not visible in the voltage evolution, one can assume a very fast physical mechanism. OES has shown that the transition from oxide to metal regime is a violent and irreversible process, leading to the destruction of $\mathrm{Al}_{2} \mathrm{O}_{3}$ at the target surface. Thus the fast increase of the energy flux density may be related to this process. One can think of the possible action of $\mathrm{O}$ - ions that are expected to be abruptly removed from the target 
at the oxide-metal transition. These ions born at the target are accelerated in the cathode sheath towards the substrate. $\mathrm{O}^{-}$ions would impact the substrate surface and transfer their high kinetic energy. The formation of negative oxygen ions in reactive sputtering have been evidenced by many authors [42-44]. Andersson et. al [44] found an increased amount of these ions during the metaloxide transition, followed by a steady state when the oxide mode is reached. Zeuner et al. [43] also reported the formation of negative oxygen ions at the cathode surface and by electronic attachment in the plasma. Mraz et a. [42] found three energetic populations of $\mathrm{O}^{-}$ions depending on their creation process. They suggested electron attachment after oxygen desorption from the target or dissociation of $\mathrm{AlO}^{-}$and $\mathrm{AlO}_{2}{ }^{-}$clusters after acceleration over the cathode fall could occur. Even if no specific study has been performed at the oxide-metal transition for decreasing $\mathrm{O}_{2} \%$, one can think that the quick destruction of the stable $\mathrm{Al}_{2} \mathrm{O}_{3}$ oxide formed at the target surface associated to an increase of the discharge voltage, would lead to the release of energetic ions. Of course $\mathrm{O}^{-}$may also be involved in the energy transfer during the oxide mode, and even at the metal-oxide transition, but they should be fewer and carry lower kinetic energy.

\subsection{Analysis of deposited thin films}

In order to get better insight into the deposition conditions during reactive magnetron sputtering process, five deposits were performed at different $\mathrm{O}_{2}$ percentages. Thicknesses, deposition rates and chemical composition are quoted in table 3.

In table 3 results from RBS analyses are given. All RBS spectra can be fitted with a single layer (i.e. a given $\mathrm{O}$ to $\mathrm{Al}$ proportion) except for sample $\mathrm{C}$ corresponding to the metal-oxide transition, for which two layers of different chemical composition should be used. XRD results are compared to the aluminum, aluminum oxide and $\gamma$-aluminum oxide JCPDS data, 040787, 100173 and 100425, respectively.

From the analyses it appears that deposits synthesized in the metal mode are polycrystallized, the only detected phase being the $\alpha$-Al. Cubic grains are visible an SEM images and the cross sections exhibit dense columnar structure (see Fig. 9). However, deposits contain non negligible amounts of oxygen as shown in table 3. Oxygen may form an amorphous oxide, at the grain boundaries for example, that would not be detected by GIXRD. Oxidation of polycrystalline $\mathrm{Al}$ films in $\mathrm{O}_{2}$ atmosphere and at low temperature is known to lead to the formation of such an amorphous $\mathrm{Al}_{2} \mathrm{O}_{3}[31,45,46]$. However, broadening and shift of the diffraction peaks are observed when the oxygen content increases in the films, indicating a modification of the crystallite size and 
lattice parameter of the Al phase. SEM image of B sample (Fig. 9) clearly shows that the grain structure evolves towards lower size. The morphology evidenced on the cross section is altered too. Formation of a $\alpha-\mathrm{Al}(\mathrm{O})$ solid solution has already been reported in reactive magnetron sputtering of Al [9]. Oxygen solubility limit as high as $28 \%$ at. was evidenced in this phase, which is well above that obtained in equilibrium conditions. Above this value, formation of oxide-type bonds was proved and an amorphous oxide was suspected to be formed. These data indicate that B deposit (containing $40 \%$ of $\mathrm{O}$ ) is certainly composed of an amorphous $\mathrm{Al}_{2} \mathrm{O}_{3}$ phase together with a $\alpha-\mathrm{Al}(\mathrm{O})$ one. It thus seems that in the metal regime oxygen atoms are progressively incorporated inside the Al phase forming the $\alpha-\mathrm{Al}(\mathrm{O})$ solid solution. If locally the $\mathrm{O}$ solubility limit is reached, oxidation may take place and an amorphous $\mathrm{Al}_{2} \mathrm{O}_{3}$ may be formed.

Sample D obtained in the oxide regime, is completely amorphous and exhibit a dense structure (not shown because the thickness of the film being low, the SEM micrograph quality was very poor). The global composition of the layer measured by RBS $\left(\mathrm{Al}_{0.3} \mathrm{O}_{0.7}\right)$ exhibits an excess of oxygen as compared to that expected for a fully oxidized compound $\left(\mathrm{Al}_{2} \mathrm{O}_{3}\right.$ : $\left.\mathrm{Al}_{0.4} \mathrm{O}_{0.6}\right)$. This has already been observed by Koski and co-workers in aluminum oxide thin films deposited by DC reactive magnetron sputtering [8].

Very interesting results are found at the metal-oxide transition. The deposit $\mathrm{C}$ lasted $35 \mathrm{~min}$. From energy flux density measurements (see the inset of Fig. 5b), it is learnt that half of the deposition process took place when conditions were continuously varying, and the other part occurred in the oxide mode. As a result, the film morphology, presented in Fig. 9 is divided in two regions: a columnar structure, characteristic of the growth in metal mode, and a dense and featureless structure. This is in agreement with RBS results evidencing two different compositions in the thickness (see table 3). The upper layer is composed of $30 \%$ of $\mathrm{Al}$ and $70 \%$ of $\mathrm{O}$, values that are obtained over the whole thickness of the sample D synthesized in the oxide mode. All these observations prove that two different compounds co-exist in the thickness of sample C: oxygen containing $\mathrm{Al}$ phase and amorphous $\mathrm{Al}_{2} \mathrm{O}_{3}$. First this shows that, in this direction (i.e. metal to oxide) it takes some time for the sputtering process to reach the oxide regime. As mentioned above, this is due to the competition between formation and destruction processes of the oxide at the target surface. In this very unstable zone, it appears thus that the growth process is close to that in the metal regime: incorporation of oxygen in the Al phase lattice. The different morphology and composition of the upper layer indicate that the growth mode was different. This may be due to the fact that other species (A1Ox), ejected from the passivated target or created in the reactive plasma, are involved in the film growth. One can expect that these species are not sensitive to oxidation. An amorphous and dense $\mathrm{Al}_{2} \mathrm{O}_{3}$ oxide grows on the substrate.

Study of the film deposited during the oxide-metal transition (decreasing $\mathrm{O}_{2}$ percentage) gives very 
interesting information too. Contrary to sample $\mathrm{C}$, sample $\mathrm{E}$ does exhibit neither a different morphology, nor a different composition in the thickness. Its features (crystalline phase, composition, morphology) are characteristic of film deposited in the metal regime. This point confirms that this transition is very sharp and that the sputtering regime turns very quickly from oxide to metal as suspected from energy flux and OES measurements. It is interesting to note that sample $\mathrm{E}$ is even better crystallized than sample A, synthesized at the same $\mathrm{O}_{2}$ percentage.

Diffraction peaks are less shifted compared to pure aluminum, and bigger grains are visible on the SEM micrograph. This is difficult to explain, but the huge energy released at the beginning of the growth (within the first minutes of the transition) may be invoked.

\section{Conclusion}

An overall study of the reactive sputtering of aluminum was carried out by coupling energy flux measurements at the substrate location with conventional diagnostics of the gas phase and analyses of the deposited films.

This work shows first, that energetic conditions of deposition are governed by the target sputtering regime, as could be expected. In metal mode it appears that oxygen is progressively incorporated in the growing aluminum film. An $\alpha-\mathrm{Al}(\mathrm{O})$ solid solution is formed and oxidation certainly takes place locally. In oxide mode, amorphous and dense deposits are obtained. The features of the films synthesized in both modes, and the corresponding values of the transferred energy, prove that the film growth process occurs in a very different manner, involving different species. This is in agreement with the decrease of $\mathrm{Al}$ line in the oxide regime where $\mathrm{AlOx}$ are expected to participate to the oxide film growth.

Original results were also obtained with the real time energy flux measurements at the transitions. Different kinetics and values of energy transfer, denoting different involved mechanisms were evidenced. The metal-oxide transition was found to be a progressive process, in agreement with OES and deposit analysis, characterized by an increase of the energy flux that could be due to the oxidation of the growing metal film. On the contrary, oxide-metal transition is abrupt, and the high energy released at the beginning could not be attributed to a chemical reaction. $\mathrm{O}$ - formed at the target and accelerated in the cathode sheath are probably responsible for this high energy release. In the $\mathrm{Al} / \mathrm{O}_{2}$ system it was found that at the metal-oxide transition, an oxide is formed by oxidation of a metallic growing film. In oxide regime, it results from the deposition of oxidized species.

This work clearly shows that studying the energetic transfers at the substrate during deposition helps understanding the growth processes and gives some insight into the involved elementary 
mechanisms taking place at the substrate.

References

[1] J. Musil, P. Baroch, J. Vlcek, K.H. Nam, J.G. Han, Thin Solid Films 475 (2005) 208.

[2] S. Wrehde, M. Quaas, R. Bogdanowicz, H. Steffen, H. Wulff, and R. Hippler, Surface and Interface Analysis 40(3-4) (2008) 790.

[3] P. Baroch, J. Musil, J. Vlcek, K.H. Nam, J.G. Han, Surf. Coat. Technol. 193 (2005) 107.

[4] D. Depla and S. Mahieu (eds.), Reactive sputter deposition, Series in Materials Science, Springer, Berlin, 2008.

[5] D. Depla, R. De Gryse, Vacuum 69(4) (2003) 529.

[6] Y. Chiba, Y. Abe, M. Kawamura, K. Sasaki, Vacuum 84(5) (2009) 629.

[7] K. Takamura, Y. Abe, K. Sasaki, Vacuum 74 (2009) 397.

[8] K. Koski, J. Hölsa, P. Juliet, Thin Solid Films 326 (1998) 189.

[9] B. Stauder, F. Perry, C. Frantz, Surf. Coat. Technol. 74-75 (1995) Part 1(0) 20.

[10] J.A. Thornton, J. Vac. Sci. Technol. 11 (1974) 666.

[11] A. Anders, Thin Solid Films 518(15) (2010) 4087 - 4090.

[12] I. Petrov, P. B. Barna, L. Hultman, and J. E. Greene, J. of Vac. Sci. Technol. A 21(5) (2003) S117.

[13] J. A. Thornton, Thin Solid Films 54(1) (1978) 23.

[14] W. D. Westwood. Sputter deposition processes. MRS bulletin 13 (1988) 6.

[15] R. Wendt, K. Ellmer, K. Wiesemann, J. Appl. Phys. 82(5) (1997) 2115.

[16] H. Kersten, H. Deutsch, H. Steffen, G.M.W. Kroesen, R. Hippler, Vacuum 63 (2001) 385.

[17] H. Kersten, D. Rohdes, J. Berndt, H. Deutsch, R. Hippler, Thin Solid Films 377-378 (2000) 585.

[18] D. J. Ball, J. Appl. Phys. 43 (1972) 3047.

[19] R. Gardon, The Rev. of Sci. Instrum. 24 (1953) 366.

[20] T.P. Düsedau, M. L. Pöhmann, F. Klabunde, T.-M. John, Surf. Coat. Technol. 133-134 (2000) 126.

[21] H. Kersten, R. Wiese, M. Hannemann, A. Kapitov, F. Scholze, H. Neumann, R. Hippler, Surf. Coat. Technol. 200 (2005) 809.

[22] K. Ellmer, R. Mientus, Surf. Coat. Technol. 116-119 (1999) 1102.

[23] P-A. Cormier, M. Stahl, A-L. Thomann, R. Dussart, M. Wolter, N. Semmar, J. Mathias, H. Kersten, J. Phys. D: Appl. Phys. 43 (2010) 465201. 
[24] R. Dussart, A. L. Thomann, L. E. Pichon, L. Bedra, N. Semmar, P. Lefaucheux, J. Mathias, Y. Tessier, Appl. Phys. Lett. 93(13) (2008) 131502.

[25] L. Bedra, A-L. Thomann, N. Semmar, R. Dussart, J. Mathias, J. Phys. D : Appl. Phys. 43(6) (2010) 065202.

[26] S. Abolmasov, P-A. Cormier, A. Torres Rios, R. Dussart, N. Semmar, A-L. Thomann, P. Roca i Cabarrocas, Appl. Phys. Lett. 100 (2012) 011601.

[27] C. Wang, P. Brault, C. Zaepffel, J. Thiault, A. Pineau, T. Sauvage,. J. Phys. D: Appl. Phys. 36(21) (2003) 2709.

[28] A.-L. Thomann, N. Semmar, R. Dussart, J. Mathias, V. Lang, Rev. of Sci. Instrum. 77(3) (2006) 033501.

[29] David R.Lide (ed.), Handbook of chemistry and physics, 73rd edition. CRC Press, INC., 1992 1993.

[30] V. Zhukov, I. Popova, Jr. J. T. Yates, proceedings of AVS 1999 volume 17, pages 1727-1732.

[31] L. P. H. Jeurgens, W. G. Sloof, F. D. Tichelaar, E. J. Mittemeije, J. Appl. Phys. 92(3) (2002) 1649.

[32] Wm.H. Krueger, S.R. Pollack, Surf. Sci. 30(2) (1972) 263.

[33] G. Dorey, Surf. Sci. 27(2) (1971) 311.

[34] S. Berg, T. Nyberg, Thin Solid Films 476 (2005) 215.

[35] K. Sarakinos, J. Alami, C. Klever, M. Wuttig, Surf. Coat. Technol. 202 (2008) 5033.

[36] F.M. Devienne, « Low Density Heat Transfer », Advances in Heat Transfer, Volume 2, Academic Press, (1965).

[37] R. Piejak, V. Godyak, B. Alexandrovich, N. Tishchenko, Plasma Sources Sci. Technol. 7 (1998) 590.

[38] D.R. Bartz, P. M. Chung, F. M. Devienne, A. B. Metzner, E. M. Sparrow, Advances in heat transfer. Academic Press, 1965.

[39] B.G. Dickins, Proc. R. Soc. Lond. A, 143:517-540, 1934.

[40] Y. Chiba, Y. Abe, M. Kawamura, K. Sasaki, Vacuum, 83(3) (2008) 483.

[41] R. Snyders, R. Gouttebaron, J. P. Dauchot, M. Hecq, J. Anal. At. Spectrom. 18 (2003) 618.

[42] S. Mraz and J. M. Schneider, J. Appl. Phys. 100(2) (2006) 023503.

[43] M. Zeuner, H. Neumann, J. Zalman, H. Biederman, J. of Appl. Phys. 83(10) (1998) 5083.

[44] J. M. Andersson, E. Wallin, E. P. Munger, U. Helmersson, J. of Appl. Phys. 100(3) (2006) 033305 .

[45] L.P.H. Jeurgens, W.G. Sloof, F.D. Tichelaar, E.J. Mittemeijer, Thin Solid Films 418 (2002) 89. [46] J.M. Khan, D.M. Makowiecki, Surf. Sci., 77 (1978) L155. 
Figure captions

Fig. 1. Schematic view of the magnetron sputtering system a) in deposition configuration, b) in configuration used for energy flux measurements.

Fig. 2. Measurement of the energy contributions due to gases/aluminum surface interaction. Numbers 1, and 3 correspond to the injection of $\mathrm{O}_{2}$, numbers 2 and 4 to the stop of $\mathrm{O}_{2}$ and $\mathrm{O}_{2}+\mathrm{Ar}$ flow rates, respectively. Before these measurements an aluminum thin film was deposited on the copper substrate.

Fig. 3. Evolution of the cathode during sputtering of Aluminum target with $\mathrm{Ar} / \mathrm{O}_{2}$ plasma.

Fig. 4. O I(777 nm)/Ar I(750 nm) (a) and Al I( $396 \mathrm{~nm}) / \operatorname{Ar~I(750~nm)~(b)~evolution~with~respect~to~}$ $\mathrm{O}_{2}$ percentage during Al- $\mathrm{O}_{2}$ magnetron sputter deposition.

Fig. 5. Typical HFM signal representing the energy influx with respect of time. First the acquisition time was equal to $30 \mathrm{~s} \mathrm{(a)} \mathrm{and} \mathrm{second} \mathrm{stabilization} \mathrm{of} \mathrm{the} \mathrm{energy} \mathrm{influx} \mathrm{value} \mathrm{was} \mathrm{waited} \mathrm{for,} \mathrm{before}$ switching off the plasma (b). Each slot corresponds to a value of the $\mathrm{O}_{2}$ percentage. The areas corresponding to the metal-oxide transition are given in inset (dotted boxes).

Fig. 6. Evolution of the energy flux density versus $\mathrm{O}_{2}$ percentages for $30 \mathrm{~s}$ and steady state signals.

Fig. 7. Energy flux density (triangles) and cathode voltage (squares) evolutions with respect to the $\mathrm{O}_{2}$ percentage during a) the increase and $\mathrm{b}$ ) the decrease of $\mathrm{O}_{2}$ percentage

Fig. 8. GIXRD patterns of sample A $\left(7.5 \% \mathrm{O}_{2}\right.$ in the gas phase, metal regime), $\mathrm{B}\left(15 \%\right.$ of $\mathrm{O}_{2}$ in the gas phase, metal regime), $\mathrm{C}\left(16.5 \%\right.$ of $\mathrm{O}_{2}$ in the gas phase, metal-oxide transition), $\mathrm{D}\left(50 \%\right.$ of $\mathrm{O}_{2}$ in the gas phase, oxide regime) and $\mathrm{E}\left(7.5 \%\right.$ of $\mathrm{O}_{2}$ in the gas phase, oxide-metal transition).

Fig. 9. SEM micrographs in plan view and cross section of sample $\mathrm{A}\left(7.5 \% \mathrm{O}_{2}\right.$ in the gas phase, metal regime), $\mathrm{B}$ ( $15 \%$ of $\mathrm{O}_{2}$ in the gas phase, metal regime), $\mathrm{C}\left(16.5 \%\right.$ of $\mathrm{O}_{2}$ in the gas phase, metal-oxide transition), $\mathrm{D}\left(50 \%\right.$ of $\mathrm{O}_{2}$ in the gas phase, oxide regime) and $\mathrm{E}\left(7.5 \%\right.$ of $\mathrm{O}_{2}$ in the gas 
phase, oxide-metal transition). 
Table captions

Table 1 : Deposition conditions. Power and pressure were kept constant at $400 \mathrm{~W}$ and $0.4 \mathrm{~Pa}$, respectively. Substrate voltage and temperature are left floating.

Table 2: Parameters used to estimate the energetic contribution of gas conduction.

Table 3: Properties of the deposited films 